\title{
Erratum to: Kuppuswamy's Socioeconomic Status Scale - Revision for 2011 and Formula for Real-Time Updating
}

\author{
Rahul Sharma
}

Published online: 3 April 2012

(C) Dr. K C Chaudhuri Foundation 2012

Erratum to: Indian J Pediatr

DOI 10.1007/s12098-011-0679-3

The original version of this article unfortunately contained a mistake.

In Table 3 and the article text, the words 'upper limit' should be read as 'lower limit'.

The online version of the original article can be found at http://dx.doi.org/ 10.1007/s12098-011-0679-3.

R. Sharma $(\triangle)$

Department of Community Medicine,

University College of Medical Sciences, UCMS \& GTB Hospital,

Delhi 110095, India

e-mail: studycorner@gmail.com 